\title{
ИСПОВЕДАЛЬНОСТЬ, ПРОПОВЕДАЛЬНОСТЬ И МЕМУАРНОСТЬ: ЦЕПЬ КЕЙС МИКРОСТАДИ
}

\author{
https://doi.org/10.34739/clit.2020.14.01
}

\section{CONFESSIONALITY, PREACHING AND MEMOIRS: CASE MICROSTUDIES}

\begin{abstract}
The author of the present study deals with the contemporary state of memoir literature based on the analysis of some recent Czech and Slovak memoirs containing a specific strategy of the heterogeneous layers of confesisons and preachings. The problem of contemporary memoir texts is connected with the position of the memoirist in the society, his/her courage and openness. The author's typology of the memoir literature is based on the three-level structure (theme, structure and genre, narrative strategy). He prefers to call it memoir literature as its structure is very heterogeneous, and the fear of the memoirist, his anxiety and aversion to express too radical views lead to soft focus, uncertainty, evasiveness, the lack of clear opinions - these are the characteristic features of contemporary memoir literature as a reflection of the state of the world and the human of the second decade of the 21 century. Due to this, the confessions and preachings have been realised in a specific manner. These features are being demonstrated at the works written by Czech and Slovak writers, significant personalities of culture, politicians, artists etc. The modern and postmodern memoir literature realizes the confessions and preachings in a specific semihidden undercurrent which is being manifested at the example of a triple structure (memoirs, portraits, textual illustrations as attachments) of the memoirs by the Slovak literary critic, hungarologist, comparatist, and translator Rudolf Chmel.

Keywords: confession - preaching, memoirs, memoir literature, memoirist, boundary genres, soft focus, uncertainty, evasiveness, the lack of clear opinion, case microstudies, semihidden undercurrent of confessions and preachings in modern memoir literature
\end{abstract}

Литературу в общем можно классифицировать по разным критериям: структурным, морфологическим, тематическим, сюжетным, жанровым и т.д. С точки зрения способа высказывания, 
можно говорить о двух типах: о литературе объективистской и исповедальной, т.е. субъективистской. С одной стороны, речь идет о нарративе, связанном с описательностью, с разными точками зрения и даже с разными рассказчиками, т.е. с гетерогенностью нарратива, с другой, о субъективистском, одномерном рассказе, об однослойности повествовательной структуры и ее построении. Оба типа характерны для разных исторических эпох, разных литературных направлений, течений и тенденций. Очевидно, что субъективные типы исповедального характера связаны скорее с теми направлениями, веяниями и художественными приемами, которые создают большой интервал между миметическим изображением и самой действительностью, о чем когда-то писал известный исследовательский коллектив чешского, теперь полузабытого или специально полностью забытого искусствоведа Савы Шабоука (1933-1993)․

Между религиозным и переносным значением слов исповедь и проповедь существует, с одной стороны, тесная связь, с другой опять-таки большой интервал, связанный с континуальным, непрерывным, генетически взаимосвязанным процессом сакрализации, секуляризации и постсекуляризации искусства и общества в целом, в том числе и литературы. Тем не менее, обе формы пронизаны демонстрацией человеческого эго, с похожими друг на друга приемами эксгибиционизма, с убеждением о значении собственной личности, о ее пророческом даровании и о непредвзятом личном опыте - все это в противовес сдержанности, краткости, скромности, лаконичности, гномичности. В то время как разные формы исповедальности и проповедальности связаны с идеалистическими эстетическими системами эмоционального и экстатического типа, например, с барокко, сентиментализмом, преромантизмом, романтизмом, разными тенденциями и направлениями модернизма, особо сильно, например, со сюрреализмом, сдержанность, лаконичность и гномичность сочетаются скорее с реалистическими типами мимесиса,

\footnotetext{
${ }^{1}$ Krátký slovník koncepce pražského týmu pro studium vyjadřovacích a sdělovacích systémů umění, ed.: Sáva Šabouk. ČSAV, Praha 1977. Русская версия: Краткий словарь межотраслевого изучения систем выражения и сообщения в искусстве. ред. С. Шабоук. В Институте теорин и истории искусств Чехословацкой Академии наук в Праге. Руководитель научного коллектива Сава Шабоук. ЧСАВ, Прага 1978. См. далее: S. Sabouk, K problematice struktur ve společenských vědách. Ústav teorie a dějin umění ČSAV, Praha 1984. Umění a skutečnost. Kolektiv mezioborového týmu pro vyjadřovací a sdělovací systémy (автором существенных разделов и сути концепции в целом был Зденек Матхаузер, чешский философ-феноменолог, русист и специалист по русскому модернизму и авангарду, чье имя нельзя было тогда по так называемым политическим причинам привести в заглавии книги). Čs. spisovatel, Praha 1976.
} 
исходящими из сокровенного проникновения в суть самой действительности, в ее подспудные слои и полускрытые пружины и механизмы, скорее скованные, редуцирующие слишком большие доли откровенности. С разными манифестациями исповедальности и проповедальности, зачастую скрытыми, можно встретиться в мемуарных жанрах, как я иногда называю жанр мемуаров, так как он теперь внутренне больше разрознен, чем когда-либо в прошлом. Проповедальность с исповедальностью в таких жанрах тесно связаны, или, точнее, одна следует из другой. Исповедь может перерасти в проповедь, когда обобщается индивидуальный опыт, который проявляется сильной визией, видением. В своих статьях и критических размышлениях я не раз упоминал особую структуру современных мемуаров, которые по-своему рефлектируют сложное состояние современного мира и роль человека в нем (в особенности в статье Правда и ложь мемуаров, в которой мы занимались некоторыми современными мемуарами, главным образом, чешскими и словацкими) $)^{2}$.

Есть исторические периоды, в которых волны мемуаров усиливаются. Это связано с общественными изменениями, историческими срывами, перерывами, политическими катаклизмами или переходными, транзитивными периодами, для которых характерно напряженное ожидание новых явлений, режимов,

\footnotetext{
${ }^{2}$ И. Поспишил, Правда и ложь мемуаров, „Conversatoria Litteraria”, Prawda i kłamstwo. Problematyka. Interpretacje. Konteksty, red. D. Szymonik, W. Krupowies, tom X, Siedlce Bańska Bystrzyca 2016, c. 21-35. I. Pospíśil, Ponorná ř eka memoárů na rozcestí, [в:] L. Pavera a kol., Metamorfózy gatunków w kontekście środkoeuropejskim. Žánrové metamorfózy $v$ stredoevropském kontextu, IV. University of Bielsko-Biała, Verbum, Praha 2009, c. 233-244. I. Pospíšil, Kvázimemoáry jako mentální signál (české a slovenské př́klady), [в:] Poetika prózy včesko-slovenských souvislostech, Ed.: I. Pospíšil, výkonná redaktorka L.Paučová. Vychází péčí České asociace slavistů ve spolupráci s Ústavem slavistiky FF MU, Slavistickou společností Franka Wollmana, Středoevropským centrem slovanských studií a ve spolupráci a s finanční podporou Literárního informačního centra v Bratislavě. Vydal Jan Sojnek - Galium, Brno 2016, c. 169-178. I. Pospíšil, Spoza Moravy (Jan Rychlík, Bohdan Zilynskyj, Paul Robert Magocsi: Dějiny Ukrajiny. Nakladatelstuí Lidové noviny, Praha 2015. Jaroslav Pánek: Češi a Jihoslované. Kapitoly z dějin vzájemných vztahů. Vydáno s podporou Společnosti přátel jižních Slovanů. Tribun EU, Brno 2015. I. Jackanin: Mit’blyskavki (Okamih blesku), Spilka ukrajinskych pis'mennykiv Slovaččyny, Prjašiv 2015. Miž Karpatami i Tatrami, vypusk 24. Užhorod, Poligrafcentr „Lira”, 2016. Novela Jána Hrušovského Dve sestry vukrajinskom preklade Ivana Jackanina. Karol Csiba: Privátne - verejné autobiografické (v memoároch a publicistike Mila Urbana, Jána Smreka, Jána Poničana, Tida J. Gašpara), Ústav slovenskej literatúry SAV, Bratislava 2014. „Slovenské pohl'ady” 2018, č. 6, c. 143-149. I. Pospíšil, Ejzenštejnova anahýza a zřetězení, [в:] Sergej Ejzenštejn, Paměti, Praha 1988, c. 425-427. I. Pospíšil, Literární historik Albert Pražák (Paměti jako poetika povinnosti a deziluze), [в:] Albert Pražák: Politika a revoluce. Paměti, eds. M. Zelenka - S. Kokoška. Ústav pro soudobé dějiny AV ČR, Výzkumné centrum pro dějiny vědy AV ČR, Praha 2004, c. 163-190. Соавтор M. Zelenka, раздел И. Поспишила na c. 177-190.
} 
общественных систем. Речь идет об исторической, личной или поколенческой расплате, оценке прошлого и, разумеется, месте мемуариста в истории.

С жанрологической/генологической точки зрения мемуары относятся к группе литературных жанров, которые находятся на грани публицистики, т. е. эстетически иррелевантной литературы, и изящной словесности, belles lettres, т. е. художественно значимой литературы. К этим жанрам принадлежат, между прочим, эссе, репортаж, фельетон, колонка, светская хроника, романическая хроника, биография и автобиография и весь пласт литературы факта, т. е. документальной прозы. В этой зоне все жанры и внутри них отдельные элементы движутся сиюминутно от одного полюса к другому: в одном превалируют эстетически значимые факторы, в другом скорее общепознавательные, без эстетических амбиций.

Кажется, верно утверждение, что нельзя писать правдивые мемуары, не только в смысле их субъективной основы как индивидуального видения мира, но и по причине страха перед ненавистью и местью изображенных лиц, перед судом, перед слишком интимным обнаружением личной жизни выступающих лиц и самого автора. В некоторых случаях особенно опасны разные политические коннотации. Разумеется, мемуары зачастую выдают тайны жизни мемуариста и подспудно и его взгляды.

Мемуары классифицируются по разным критериям. Мы обычно прибегаем к трехступенчатой типологии, а именно: по тематическому диапазону, по структурно-жанровым признакам и по нарративно-стратегическим аспектам. В современной литературе встречается сравнительно много мемуаров, которые я предлагаю называть скорее мемуарными текстами, так как они синтезируют признаки нескольких жанровых пластов. Это, наверное, связано и с коренным вопросом о правдивости и лживости мемуаров как таковых 3.

С одной стороны, мемуары повествуют об окружающей автора действительности и о его отношении к разным людям и событиям. С другой, это именно своего рода исповедальный и проповедальный текст, явно или скрыто выражающий внутренние психические процессы в авторском сознании. В рамках первого аспекта общепринятым является тезис, согласно которому лучше мемуары не писать, так как нельзя достигнуть их исторической правдивости. Это дано их внутренним строением, а также известными внешними факторами, давлением общественной

\footnotetext{
3 Этот раздел настоящей статьи опирается на текст нашего исследования: Правда и ложь мемуаров..., ор. cit., с. 21-35.
} 
и политической ситуации на автора, которое приводит к тому, что мемуарист слишком сильно старается избегать конфликтов, судебных дел, вообще того, что могло бы ему повредить, например, в быту, в профессии и т.д., как мы об этом писали выше. В современном обществе такие опасения вполне оправданы, так как человек больше, чем когда-либо в прошлом, является лишь игрушкой тайно правящих сил, которые нельзя точно идентифицировать.

В рамках второго аспекта, т. е. сообщающихся сосудов исповедальности и проповедальности, то, что характеризует современные мемуары, - это их гетерогенность и завуалированность; современные мемуары страдают зачастую недостатком смелости, особенно в отношении крайних взглядов, дефицитом выразительной индивидуальности, перестраховкой и оценочной посредственностью. Мемуары, таким образом, представляют собой лакмусовую бумажку этой тяжелой болезни нашей эпохи.

Того, кто превышает посредственность, обычно ликвидируют. Достаточно только посмотреть сегодня на официальных государственных должностных лиц европейских государств и сравнить с прошлыми десятилетиями - даже несмотря на изменения режимов и политических систем, число настоящих личностей ранее преобладало над необразованными или поверхностно образованными людьми, пребывающими в ладу со всеми, что невозможно для сильных личностей. Таким образом, исповедальная и в результате и проповедальная ценность мемуаров как жанра, который выражает субъективное видение мира и человека, ослабевает.

Мемуары выступают зачастую в скрытой и завуалированной жанровой форме, в нарративных масках, в которых собственные авторские взгляды мемуаристов спрятаны под пластом других высказываний, мета- или же метаметатекстов; все подается косвенным образом. В разных своих статьях я отмечал их размытость, расфокусирование, неуверенность, эвфемистичность, уклончивость.

В структуре кейс микростади мы не раз анализировали разные чешские и словацкие тексты, в том числе и чешского специалиста по романским литературам, литературного критика и издателя известного Критического месячника (Kritický měsíčník), подписанта Хартии 77, можно лишь добавить, что это типичные мемуары „angry old man”, разгневанного интеллектуала Вацлава Черного (1905-1987). Они - плоды „драконова посева” представляют собой классическую мемуарную структуру, т.е. анализ судьбы человека под давлением исторического времени, причем 
текст насыщен выразительными характеристиками разных общеизвестных лиц, по крайней мере в чешской среде4.

Примером современного варианта классических мемуаров могут служить мемуары Ладислава Штаидла, известного чешского музыканта и композитора, представителя „среднего течения” чешской популярной музыки 60-80-х годов 20 века5. Мемуары являются традиционной цепью разного рода историй, из которых следует главное поучение: каждое время приносит хорошее и плохое, живут в нем добрые и злые люди, нельзя ссылаться на неблагоприятные условия. Искреннее изложение событий зачастую анекдотического характера, пронизывающая все ирония и самоирония и описание многочисленных любовных приключений автора придает мемуарам классический оттенок откровенности. Единственной нарративной маской мемуариста остается ироническая отстраненность, сдержанность и трезвость. Характерно и то, что так называемое социалистическое прошлое он видит не схематично - это время, заполненное свежими новыми идеями и человеческими судьбами. С этим связан и определенный сдержанный пессимизм и, может быть, легкий, но опять-таки субъективно правдивый цинизм мемуаров ${ }^{6}$.

В виде исключения встречаются мемуары духовной жизни, скрытые под дневником читателя, как, например, в книге Антонина Гоштялека (Hoštálek 2015)7. Исповедальность постепенно переходит в скрытую проповедальность в смысле образа будущей жизни.

Особый вид мемуаров образуют воспоминания политических лиц или людей, которые тесно связаны с важными событиями политической и культурной жизни ${ }^{8}$.

Именно в таких текстах видно, что классификация или типология мемуаров вытекает также из нарративной стратегии. В некоторых мемуарах речь идет, главным образом, об изображении среды и людей, в других это скорее автобиография мемуариста,

\footnotetext{
4 V. Černý, Paměti (I). 1921-1938. Brno 1994. Paměti (II). Křik Koruny české: 1938-1945. Náš kulturní odboj za války. Brno 1992. Paměti (III): 1945-1972, Brno 1992.

5 L. Štaidl, Víno z hrozmù. Praha 2003. Cм. I. Pospíšil, Souvislosti dnešní české a slovenské prózy a jedna provokativní marginálie (Víno z hroznů Ladislava Štaidla), [в:] Kpoetologickým a axiologickým aspektom slovenskej literatúry po roku 1989, Prešov 2006, c. 237-250.

${ }^{6}$ См. И. Поспишил, Правда и ложь мемуаров..., ор. cit., с. 21-35.

7 A. Hoštálek, Deník čtenáře 2014-2015, Brno 2015.

8 M. Uhde, Rozpomínky. Co na sebe vím, Praha a Brno 2013. V. Válek, K specifičnosti memoárové literatury, Brno 1984. J. Vanovič, Zápisky z mŕtveho času/ Antimemoáre, Bratislava 2014. S. Volný, Od totality $k$ demokracii anebo Jak jsem se dočkal listopadové revoluce. Rozhovory s Richardem Seemannem během let 2012-2013, Praha 2014. J. Vondráčková, Mrazilo - tálo (O Jiř́m Weilovi), Praha 2014. Život mimo kategorie. Rozhovor Jana Nováka s Johnem Bokem, Praha - Litomyšl 2015.
} 
темой является особый эгоцентризм автора - все сосредоточивается на нем и на его проблемах и страданиях 9 . Мемуары Вановича сродни воспоминаниям профессора Карлова Университета, известного чешского русиста и балтиста Радегаста Паролека (Parolek 2013): гиперболизация лица мемуариста, который является центром всего, метод портретов видных лиц, изложение которых зависит от отношения к мемуаристу ${ }^{10}$.

Совсем иными кажутся мемуары с продолжением другого профессора Карлова Университета Милана Гралы (1931-2015), известного специалиста по русской советской литературе, в особенности сатире, и транслатологии (Hrala 2010, 2014, 2007). Концепция его воспоминаний исходит из мозаики историй, маленьких глав или разделов, зачастую анекдотического характера ${ }^{11}$.

Примером мемуаров интенсивного исповедального характера могут служить - кроме уже упомянутого текста Милана Гралы - интересно структурированные воспоминания Рудольфа Хмела $^{12}$, словацкого венгроведа, литературоведа, компаративиста и переводчика, университетского доцента и доктора наук, политика, министра, первого и последнего посла Чехословацкой Федеральной Республики, словакиста в Карловом Университете. Его личность уже не раз оценивалась более информированными и компетентными исследователями. Автор образовал своеобразную структуру: в начале находятся настоящие воспоминания с сильной концентрацией исповедальности, слабее представлен слой проповедальности, далее портреты отдельных лиц, с которыми автор часто встречался и, в конце концов, разнородные тексты, главным образом, политические и культурно-политические, которые иллюстрируют отдельные этапы авторской жизни, придавая его воспоминаниям оттенок аутентичности и документальности. Типично уже название книги воспоминаний как особого „введения” в тему памяти, т. е. как какой-то предварительный этап. Текст Хмела хорошо читается, автор здраво скептичен, деликатен, ненавязчив. Он избрал типичный, умный, даже хитрый подход, и, таким образом, создал функциональный фон для его собственного повествования. В работе под названием

\footnotetext{
9 J. Vanovič, Zápisky z mŕtveho času/ Antimemoáre. Bratislava 2014.

${ }^{10}$ R. Parolek, Kruté i krásné dvacáté století. Memoárová mozaika v pěti dílech, Praha 2013.

${ }^{11} \mathrm{~B}$ моей не раз цитируемой статье, на результаты которой я опираюсь и здесь (Правда u ложь мемуаров, op. cit, с. 21-35), упоминаются и разные другие мемуары разного жанрового типа.

12 R. Chmel, Úvod do pamäti, Bratislava 2019.
} 
Память против истории он обращается к особой теории мемуаров, что его следующему тексту придает самоироничное и метатекстуальное значение; таким образом, теряется слишком интенсивная знаковость литературного текста. Его мнение о мемуарах включает в себя абсолютную релятивизацию памяти, что представляет собой умный прием, подход, который биологически и этически объясним, т. е. обыкновенная забывчивость и избирательность памяти, что подтвердит каждый психолог - и - во всяком случае она понятна с общечеловеческой точки зрения. Посредством упомянутой стратегии скромности и релятивизации автор приобретает симпатии читателей, но, может быть, не всех. И это подтверждается тем, что автор - любимец фортуны, чему он способствовал своим осторожным, сдержанным, рассудительным, благоразумным подходом, что, разумеется, особенно в сфере политики, полезно и умно: такие мемуары никого не расстраивают, не огорчают, хотя автор не меняет свои коренные взгляды. Похоже, что он всегда стоял на правильной стороне, иногда громко, иногда тише, но всегда боролся за правое дело и зачастую добивался правды, что у него не могло не быть конфликтов, но он сам их не искал, будучи человеком насквозь прагматичным, бесконфликтым, т. е. и его конфликты были скорее притушенными. В такой стратегии исповедальности мемуаров многое говорит об авторе и разных лицах и ситуациях, менее о контекстуальных связях событий. Отдельные события можно рассматривать и оценивать подругому; особенно интересными для познавания истории словацкой культурной жизни, главным образом, 60-90-х гг. 20 века, большой интерес представляют его комментарии относительно словацкой истории, политики, специфики словацкой ментальности вне и даже против хрестоматийного изложения. Все анализируется деликатно, но точно, включая и события бархатной или, как в Словакии предпочитают говорить, нежной революции. Ключевой фигурой является поэт, министр и политик Мирослав Валек, хотя авторский взгляд на него в этом отношении сдержанный, но более или менее объективный, хорошо аргументированный.

Особое внимание уделяется - в цепи намеков на разные мемуары и их исповедальность и проповедальность в форме кейс микростади - именно этому свежему произведению, относящемуся к этом году, можно объяснить именно специфической стратегией повествования и оценки и подхода к действительности. Кроме того, именно место и структура исповедальности и проповедальности отличает упомянутый текст от других, о которых писалось выше, a также в других моих исследованиях. Специфическая черта заключается именно в том, что исповедальные части 
демонстрируются сдержанно, косвенным образом, обычно в рамках общих оценок и стратегии объективации авторского субъекта, проповедальные результаты обнаруживают ту же сдержанность и манифестируются скорее отрывисто, несколькими предложениями, скорее характером упоминаемых эпизодов. Эта стратегия особым образом, т. е. в рамках специфической формы остранения, проявляется именно в описании ключевых общественных событий, менее в эпизодах, носящих скорее личный, интимный характер.

Именно в мемуарных жанрах, стоящих на грани аутентичности, документальности и художественности, исповедальные текстуальные пласты функционируют как полускрытые, подспудные знаковые структуры, по-новому выражающие древние морфемы исповеди как религиозного коммуниката, выразителя вероисповедания, разговора с высшими силами. В разделе-кейс микростади о мемуарах Рудольфа Хмела демонстрируется своего рода оригинальное возобновление старинного исповедального дискурса в форме подспудного изречения и полускрытой (повторы) проповеди как модернизированного высказывания и свидетельства о человеческом существовании.

В качестве добавления к настоящей рефлексии, исходящей из некоторых мемуарных текстов чешской и словацкой литератур, можно подытожить: личный опыт автора настоящей статьи подтверждает искренность автора мемуаров, который не притворяется и вполне естественно неретушированно, будто бы незаметно аргументированно выражает в исповедальных изречениях свои взгляды, так что они становятся приемлемыми или по крайней мере объектом серьезной дискуссии. Жаль, что автор мемуаров избежал конфронтации с другими концепциями словацкой истории и политической жизни, что он показал слишком одностороннюю Словакию. Исповедальная форма мемуаров как особого синтеза гетерогенных текстов воспоминаний, портретов, текстуальных приложений - это все позволяет заполнить белое пятно в стратегии исповедальности и проповедальности современной (наиболее перспективного типа) литературы, стоящей на грани документальности и художественности. 


\section{Литература/ References}

Bagin A., Pokus o charakteristiku memoárovej literatúry, „Slovenská literatura" 1977, 2, s. 170-179.

Andrš B., Česká Alexandrovka. Vzpomínky na život české vystěhovalecké komunity na Rusi, Praha 2015.

Blažíčková A., Ted' něco ze života, Praha 2012.

Černý V., Paměti (I). 1921-1938, Brno 1994.

Černý V., Paměti (II). Křik Koruny české: 1938-1945. Náš kulturní odboj za války, Brno 1992

Černý V., Paměti (III): 1945-1972, Brno 1992.

Čorná T., Kornel Földvári, Bratislava 2014.

Haugová M., Písat'ako dýchat' (Siet'vody s tisícimi vchodmi), Bratislava 2014. Hoštálek A., Deník čtenáře 2014-2015, Brno 2015.

Dorovský I., S domovem v srdci, Brno 2014.

Hrala M., Všecko bylo/ bude trochu jinak, Ústí nad Orlicí 2010.

Hrala M., Všecko bylo trochu jinak. Dodatky, Ústí nad Orlicí 2014.

Jeřábek Č., V pamèti a v srdci. Životní vzpomínky, Brno 1961.

Jeřábek Č., V zajetí stalinismu. Z deníků 1948-1958, Brno 2000, 2008.

Kusý I., Memoáre ako svedectvo rozhrania, „Slovenská literatura” 1979, 3, S. 217-238.

Parolek R., Kruté i krásné dvacáté století. Memoárová mozaika v pěti dílech, Praha 2013.

Petránek J., Na co jsem si ještě vzpomněl. Privátní encefalograf našeho tak málo lidského XX. století, Praha 2014.

Pospíšil I., Ejzenštejnova analýza a zřetězení, [в:] Sergej Ejzenštejn, Paměti, Praha 1988, c. 425-427.

Pospíšil I., Když se nevyčasí aneb Stmívání, Brno 2015.

Pospíšil I., Kvázimemoáry jako mentální signál (české a slovenské příklady), [в:] Poetika prózy v česko-slovenských souvislostech, ed. I. Pospíšil, výkonná redaktorka: L. Paučová, Brno 2016, c. 169-178.

Pospíšil I., Literární historik Albert Pražák (Paměti jako poetika povinnosti a deziluze), [в:] A. Pražák, Politika a revoluce. Paměti, ed. M. Zelenka S. Kokoška, Praha 2004, s. 163-190.

Pospíšil I., Ponorná řeka memoárů na rozcestí, [в:] Libor Pavera a kol.: Metamorfózy gatunków $w$ kontekście środkoeuropejskim. Žánrové metamorfózy $v$ středoevropském kontextu, IV. University of BielskoBiała, Verbum, Praha 2009, c. 233-244.

Pospíšil I., Правда и ложь мемуаров, „Conversatoria Litteraria“, tom 10, Prawda i kłamstwo. Problematyka. Interpretacje. Konteksty, red. D. Szymonik, W. Krupowies, Siedlce - Bańska Bystrzyca 2016, c. 21-35.

Pospíšil I., Souvislosti dnešní české a slovenské prózy a jedna provokativní marginálie (Víno z hroznů Ladislava Štaidla), [в:] K poetologickým a axiologickým aspektom slovenskej literatúry po roku 1989. Prešov 2006, c. 237-250. 
Pospíšil I., Spoza Moravy (Jan Rychlík, Bohdan Zilynskyj, Paul Robert Magocsi: Dějiny Ukrajiny. Nakladatelstú Lidové noviny, Praha 2015.

Pánek J., Češi a Jihoslované. Kapitoly z dějin vzájemných vztahủ, Brno 2015. Jackanin I., Mit' blyskavki (Okamih blesku). Spilka ukrajinskych pis'mennykiv Slovaččyny, Prjašiv 2015, „Miž Karpatami i Tatrami“, vypusk 24, 2016. Novela Jána Hrušovského Dve sestry v ukrajinskom preklade Ivana Jackanina.

Csiba K., Privátne - verejné - autobiografické (v memoároch a publicistike Mila Urbana, Jána Smreka, Jána Poničana, Tida J. Gašpara), Bratislava 2014.

Šikulová V., Freska v dome, Bratislava 2014.

Štaidl L., Víno z hroznů, Praha 2003

Štrasser J., Byt’svoj. Rozhovory s Jánom Buzássym, Bratislava 2013.

Šuša I., Holokaust v talianskej a slovenskej memoárovej literatúre, Brno 2009.

Trzynadlowski J., Struktura relacji pamiętnikarskiej, [в:] Księga pamiątkowa k czci Stanistawa Pigonia, Kraków 1961, c. 577-583.

Uhde M., Rozpomínky. Co na sebe vím, Praha a Brno 2013.

Válek V., K specifičnosti memoárové literatury, Brno 1984.

Vanovič J., Zápisky z mŕtveho času/ Antimemoáre, Bratislava 2014.

Volný S., Od totality k demokracii anebo Jak jsem se dočkal listopadové revoluce. Rozhovory s Richardem Seemannem během let 2012-2013, Praha 2014.

Vondráčková J., Mrazilo - tálo (O Jiřím Weilovi), Praha 2014. 